4 Eugen Egorov ${ }^{\mathrm{a}, *}$, Martin M. Gossner ${ }^{\mathrm{b}, \mathrm{c}}$, Sebastian. T. Meyer ${ }^{\mathrm{b}}$, Wolfgang W. Weisser ${ }^{\mathrm{b}}$, Martin

5 Brändle ${ }^{\mathrm{a}}$

\section{Does plant phylogenetic diversity increase invertebrate herbivory in managed grasslands?}

${ }^{a}$ Department of Ecology - Animal Ecology, Faculty of Biology, Philipps-Universtät Marburg, Karl-vonFrisch Str. 8, 35043 Marburg

${ }^{b}$ Terrestrial Ecology Research Group, Department of Ecology and Ecosystem Management, School of Life Sciences Weihenstephan, Technical University Munich, Hans-Carl-von-Carlowitzplatz 2, 85350 Freising-Weihenstephan, Germany

E-mail address: eugen.egorov@staff.uni-marburg.de.

This document is the accepted manuscript version of the following article: Egorov, E., Gossner, M. M., Meyer, S. T., Weisser, W. W., \& Brändle, M. (2017). Does plant phylogenetic diversity increase invertebrate herbivory in managed grasslands? Basic and Applied Ecology, 20, 40-50. https://doi.org/10.1016/j.baae.2017.03.004 


\section{Abstract}

Plant diversity and land-use intensity have been shown to affect invertebrate herbivory. Several hypotheses predict positive (e.g. associational susceptibility) or negative (e.g. associational resistance) relationships of herbivory with plant species richness. Also, the strength and direction of reported relationships vary greatly between studies leading to the conclusion that relationships either depend on the specific system studied or that other unconsidered factors are more important. Here, we hypothesized that plant phylogenetic diversity is a stronger predictor of invertebrate herbivory than plant species richness because it integrates additional information about the phenotypical and functional composition of communities. We assessed the communitywide invertebrate herbivory, plant species richness and phylogenetic diversity across a range of land-use intensities including a total of 145 managed grasslands in three regions in Germany. Increasing land-use intensity decreased plant species richness and phylogenetic diversity. Plant species richness did not predict invertebrate herbivory. By contrast herbivory moderately increased with increasing plant phylogenetic diversity even after accounting for the effects of region and land use. The strength of direct effects of land-use intensity and indirect effects via altered phylogenetic diversity on herbivory, however, varied among regions. Our results suggest that increasing phylogenetic diversity of plant communities increases invertebrate herbivory probably by providing higher resource diversity. Differences between regions underline the need to account for regional peculiarities when attempting to generalize land-use effects on invertebrate herbivory.

Keywords: Biodiversity Exploratories, land use, ecosystem process, insects, phylogeny 


\section{$34 \quad$ Introduction}

Plant diversity and land-use intensity affect aboveground invertebrate herbivory (e.g. Scherber et al. 2006; Scherber et al. 2010; Loranger et al. 2014; Gossner et al. 2014). Previous studies that focused on responses of herbivory to changes in plant species richness revealed, however, no consistent patterns: there is an approximately equal number of studies reporting either positive or negative relationships between herbivory and plant species richness (reviewed in Meyer et al. submitted; Dinnage 2013). Several theoretical predictions can be made about the relationship between herbivory and plant species richness. For example, the associational resistance hypothesis (Tahvanainen \& Root 1972) states that increasing number of plant species reduces invertebrate herbivory. This has been shown in meta-analysis approaches for crop fields (Letourneau et al. 2011) and forests (Castagneyrol et al. 2014). The mechanisms behind this can be for example resource dilution effects for specialist herbivores, interaction between plants and natural enemies (Stiling et al. 2003) or chemical compound release depending on the neighboring plants (Himanen et al. 2010). On the other hand, associational susceptibility predicts increased herbivory with increasing plant diversity. For example, increasing plant species richness can provide a wider array of additional nutritional resources for a higher number of herbivore species, the so-called dietary mixing hypothesis (after Bernays et al. 1994). Several studies have shown a positive correlation between plant species richness and invertebrate (e.g. Unsicker et al. 2008; Plath et al. 2012; but see Guyot et al. 2016 for negative correlation and Kambach et al. 2016 for no effect of plant diversity and herbivory). Studies which included additional predictors such as functional composition of plant communities found no relationships between plant species richness and herbivory (Scherber et al. 2006; Scherber et al. 2010), leading to the conclusion that plant species richness is not a major driver of herbivory. That might be because species richness is only a coarse and very simple descriptor for diversity within ecological communities. Other descriptors like community phylogenetics can integrate information on various plant traits, which might be related to herbivory but often are difficult to assess (for instance biochemical defense mechanisms; Wink 2003) into a phylogenetic diversity index. Several studies already focused on the effect of community phylogenetics, in addition to species richness, on herbivory and showed that increasing phylogenetic diversity of plant communities is often associated with decreasing herbivory (e.g. Yguel et al. 2011; Dinnage 2013; Castagneyrol et al. 2014) supporting the associational resistance hypothesis. Compared to this, only few studies have found a positive effect of phylogenetic diversity on herbivory (Parker 
et al. 2012; Schuldt et al. 2014). However, to date, most studies on phylogenetic diversity and herbivory have been carried out in forests and/or artificial or experimental communities, and thus, are lacking information about the processes in semi-natural communities under "real-world" conditions, particularly in grasslands. Previous studies on the effects of phylogenetic diversity on herbivory have used two approaches to assess herbivory. In the first approach, herbivory is measured on one ("focal") plant species in monocultures/low diversity plots and within high diversity plots. In a recent meta-analysis, using this approach, Castagneyrol et al. (2014) showed that herbivory on trees in mixed and pure forests depended on herbivore specialization and plant phylogenetic diversity. While damage caused by specialist herbivores was related only to the abundance of their focal host plants, herbivory caused by generalists decreased in mixed forests, but only when host trees and associated trees were distantly related. In a second approach, herbivory is measured at the community level, where herbivory on all plant species is assessed. Using this measure of herbivory, Dinnage (2013) showed that although herbivory decreased weakly with increasing plant phylogenetic diversity, there was a significant interaction between plant species richness and phylogenetic diversity. Increasing plant species richness increased invertebrate herbivory, but the strength of this effect decreased with increasing plant phylogenetic diversity. By contrast, a meta-analysis by Parker et al. (2012) found an increase of herbivore damage with increasing phylodiversity of plants. The authors explained this pattern with increasing generalist herbivore damage. The contrasting results indicate that the strength and direction of the effect depend on the system studied and consequently on plant and herbivore community composition (e.g. functional composition of plant communities, specialist-generalist ratio, feeding guilds). For example, Dinnage (2013) excluded grasses from his analyses and focused only on forbs. However, grasses dominate grassland communities in terms of abundance and therefore are an important resource for herbivores. At the same time grass occurrence decreases phylogenetic diversity of plant communities especially when plant abundance is considered. Thus, in studies focusing on invertebrate herbivory in natural or semi-natural grasslands, the abundance of grasses could directly and indirectly (via decrease in plant phylogenetic diversity) affect herbivory.

In addition to biotic interactions, anthropogenic pressure (i.e. land-use intensification) can affect invertebrate herbivory. Gossner et al. (2014) showed that invertebrate herbivory in temperate managed grasslands decreased with increasing land-use intensity at the local scale. The authors hypothesized that several direct and indirect effects of increased land-use intensity might cause a decrease in herbivory, e.g. direct effects of mowing on herbivores by killing arthropods or indirect effects via reduced plant species richness and an 
increased proportion of grasses. At the same time land-use intensification has been shown to decrease phylogenetic diversity of plant communities (Dinnage 2009) and thus, an indirect effect of land use on herbivory might also be caused by changes in phylogenetic diversity.

In this study we focus on invertebrate herbivory in temperate grasslands of differing management. We aim to analyze the relationships between grassland management intensity (henceforth 'land-use intensity'), plant diversity and herbivory by using a comprehensive dataset of 145 grassland plots in three regions in Germany. We hypothesize that plant phylogenetic diversity is a stronger predictor of herbivory than plant species richness because phylogenetic diversity integrates more information on community structure and phenotypic and functional composition of plants, that are important determinants of invertebrate herbivory, than simple measures of species richness (Scherber et al. 2010; Parker et al. 2012; Dinnage 2013). Specifically we expect to find either a positive relationship between herbivory and plant phylogenetic diversity on the community level (due to associational susceptibility) or a negative relationship (due to associational resistance of diverse plant communities). We also hypothesize that indirect effects of land use on herbivory via changes in plant communities (species richness, proportion of grasses and phylogenetic diversity) are more important than direct effects because of the strong link between herbivores and their hosts. In particular we predict that indirect land-use effects are primarily mediated by changes in phylogenetic diversity of plant communities that are also coupled to changes in species richness and proportion of grasses.

\section{Materials and methods}

\section{Study region}

Our study was conducted within the Biodiversity Exploratories (www.biodiversity-exploratories.de), a largescale and long-term project on the relationships between land-use intensity, biodiversity and ecosystem functioning. The Biodiversity Exploratories consist of three regions in Germany (Schwäbische Alb (Alb); 460 $860 \mathrm{~m}$ a.s.1., $48^{\circ} 43^{\prime} \mathrm{N} 9^{\circ} 37^{\prime} \mathrm{E}$; Hainich-Dün (Hainich): 285-550 $\mathrm{m}$ a.s.1., 51 ${ }^{\circ} 20^{\prime} \mathrm{N} 10^{\circ} 41^{\prime} \mathrm{E}$; and Schorfheide-

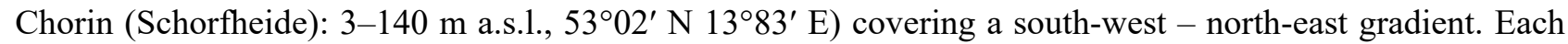
region comprises 50 grassland plots of different land-use types; meadows, pastures, and mown pastures, that 
were either fertilizes or unfertilized). The studied plots represent the regional range of land-use intensities considering mowing, grazing, and fertilization. Annual mean temperature and precipitation in Alb, Hainich and Schorfheide is $6-7^{\circ} \mathrm{C}$ and $700-1000 \mathrm{~mm}, 6.5-8{ }^{\circ} \mathrm{C}$ and $500-800 \mathrm{~mm}$, and $8-8.5{ }^{\circ} \mathrm{C}$ and $500-600 \mathrm{~mm}$, respectively. For more details see Fischer et al. (Fischer et al. 2010).

\section{Land Use}

Land-use information of the study plots was obtained by yearly interviews with farmers and land-owners between 2006 and 2013. Due to variability in land-use intensity between years (Blüthgen et al. 2012), we used the mean of all years to better cover the long-term management. Information on three components of land use was acquired; fertilization intensity (kg nitrogen ha-1 year-1), mowing frequency (number of cuts year-1), and grazing intensity (livestock units $\times$ days of grazing ha-1 year -1 ). The land-use components were standardized and summed up to a combined quantitative land-use intensity index (LUI; Blüthgen et al. 2012) using the formula

$$
\mathrm{L}_{i}=\frac{\mathrm{F}_{i}}{\mathrm{~F}_{R}}+\frac{\mathrm{M}_{i}}{\mathrm{M}_{R}}+\frac{\mathrm{G}_{i}}{\mathrm{G}_{R}}
$$

where $\mathrm{F}_{i}, \mathrm{M}_{i}$ and $\mathrm{G}_{i}$ are fertilization intensity, mowing intensity and grazing intensity on site $i$ and $\mathrm{F}_{R}, \mathrm{M}_{R}$ and $\mathrm{G}_{R}$ are the respective regional means. The yearly LUI-values were averaged for each of the plots for the fiveyear period and the obtained means were used for our analyses. The LUI values were bound between 0.5 (low intensity) and 3.5 (high intensity).

\section{Plant species richness, functional composition and phylogenetic} diversity

Between 2009 and 2011 vegetation on a $4 \mathrm{~m} \times 4 \mathrm{~m}$ subplot in each grassland plot was analyzed yearly. For each plot, vascular plant species richness and their relative abundance in percent cover was estimated. Based on these data we calculated the species richness as the average richness per plot across the three years. In addition, the proportion of grasses was estimated as the proportion of total biomass (Gossner et al. 2014) in all samples of the herbivory assessment (see below).

Phylogenetic relatedness of species was obtained from a well resolved and dated phylogeny of the Central 
European flora (Durka \& Michalski 2012). In brief, this phylogeny was assembled by manually grafting subtrees on a backbone topology, dating of nodes based on fossil records using the bladj algorithm in PHYLOCOM (Webb et al. 2008) and calculating an ultrametric tree (for details see Durka \& Michalski 2012). We pruned the overall phylogeny to match the species pool of each of the three regions. As a result we obtained three trees, one for each region, representing the phylogenetic relationships of the respective species pool. Phylogenetic diversity of plant species was calculated with the "picante" package in R (Kembel et al. 2010). For each plot and year, we calculated the mean pairwise distance (MPD) (Webb et al. 2002). We then calculated averages across the three years and used the mean MPD for each plot for further analyses (Egorov et al. 2014). Phylogenetic diversity was calculated using presence/absence and abundance-weighted data (\% cover), which were moderately correlated $(\mathrm{r}=0.5)$. In general, results based on presence/absence and abundance data did not differ strongly and since abundance of (potential host) plants plays a major role in herbivore plant diversity relationships (Root 1973; Solomon 1981; Otway et al. 2005) we focus here on results based on abundance-weighted data.

\section{Herbivory}

Herbivory was measured in all plots in May 2013 before mowing took place (see Gossner et al. 2014). To prevent livestock grazing temporary electrical fences were installed in early spring. Five plots had to be excluded from analysis since grazing by cattle in the fenced patches had likely occurred, resulting in a total of 145 analyzed plots. In each plot, vegetation was cut on two $10 \mathrm{~cm} \times 45 \mathrm{~cm}$ random subplots and from each sample 100 leaves were collected randomly from grasses and forbs relative to their estimated proportion of biomass in the sample, totaling in 200 leaves per plot. Damaged leaf area was estimated by eye using templates leaf damage; chewing (hole and margin feeding caused by e.g. caterpillars, adult and juvenile beetles), sap sucking (punctures caused by e.g. Hemiptera), leaf mining (mines caused e.g. by Diptera: Agromycidae), and rasping (feeding on upper or lower side of the leaf while the other side remains intact, cause by e.g. sawfly larvae). The leaf area remaining after herbivory was measured for all leaves using a leaf-area-meter (LI-3000C, Lincoln (NE) USA). Proportion of leaf area damaged was calculated by dividing damaged area by the sum of measured remaining leaf area and damaged area. Herbivory values were transformed to proportions on the interval $(0,1)$ for beta regression analyses and arcsine-square-root transformed for all other analyses to 
approximate normality.

\section{Statistical analyses}

To test which plant diversity measure is the best predictor for invertebrate herbivory, we used region and each measure (proportion of grasses, species richness and phylogenetic diversity) as a single predictor and all three combined in a beta regression model with invertebrate herbivory as the response variable. We used the package betareg in R (Cribari-Neto and Zeileis 2010) to perform beta regressions. Beta regression is a suitable method to analyze beta distributed proportion data defined on the interval $(0,1)$. We then used the function Irtest implemented in the package "Imtest" to compare the log-likelihood of the models. In addition, we calculated the AIC and BIC scores for each model.

We examined the effects of land use and different plant diversity measures on invertebrate herbivory with the model:

herbivory $\sim$ region + land-use intensity + proportion of grasses + plant species richness + plant phylogenetic diversity, where the region term was included to account for the different region specific conditions (abiotic, biogeographic, etc.).

To test for the effect of plant phylogenetic diversity independent of region, land-use intensity, proportion of grasses and plant species richness we also used sequentional type I ANOVAs with region, LUI, grass proportion and plant species richness being the first variables fitted in the model. Plant phylogenetic diversity was fitted last to test whether it explains additional variation in herbivory. Sequentional analysis of variance to test for effects of phylogenetic diversity after accounting for other variables cannot be carried out with beta regression models, thus we used simple linear models after transforming herbivory values to approximate normality.

We also tested for potential interactions between region/land-use intensity and plant diversity. There were, however, no interactions between these variables in any model tested. In the same sense we tested for and found no interactions between plant phylogenetic diversity and plant species richness. Thus, we did not include these interactions into the models.

We further used structural equation modeling calculated with the package "lavaan" (Rosseel 2012) to test if 
previously observed land-use effects on herbivory were indirect effects mediated by the proportion of grasses, plant species richness and plant phylogenetic diversity. In the model we defined herbivory, proportion of grasses and plant diversity (species richness and phylogenetic diversity) as being affected by land use (oneway arrows in the diagrams). We further stated that herbivory is affected by plant species richness and plant phylogenetic diversity as well as proportion of grasses. Since higher proportion of grasses can decrease the mean phylogenetic distance between species in assemblages we also defined that plant phylogenetic diversity is affected by the proportion of grasses. And finally we assumed that plant species richness and plant phylogenetic diversity correlate with each other (two-way arrows in the diagrams). Based on the $\chi^{2}$ statistic, the model for Schorfheide provided a bad fit and did not converge well. Therefore, we excluded the least significant variable (highest $p$-values) form the model (i.e. plant species richness), which resulted in a better fit of the data, however, the model became saturated. In addition, we used the hierpart function in the hier.part package to assess how much of the variation in herbivory was explained by land-use intensity and plant diversity in the three regions separately and combined. All analyses were conducted in R 3.0.3 (R Core Team 2014).

\section{Results}

Mean number of plant species per plot in the three years was 26.9 (min: 13.3; max: 55.6). Mean phylogenetic diversity (mean pairwise distance in million years) was 192.1 (min: 55.9; max: 242.2). Average herbivory in the three regions was $1.05 \%$ (min: $0.05 \%$; max: $5.6 \%$ ). Herbivory rates differed between regions $\left(\mathrm{F}_{2,142}=9.78\right.$, $p<0.001)$ with highest mean rates observed in Schorfheide $(1.26 \% \pm 0.15 \mathrm{SE})$ followed by Alb $(1.22 \% \pm 0.08$ $\mathrm{SE})$ and Hainich $(0.68 \% \pm 0.07 \mathrm{SE})$.

Herbivory increased moderately with increasing phylogenetic diversity of plant communities when using beta regression (Fig.1) and linear models. When using beta regression, plant phylogenetic diversity was the best single predictor for invertebrate herbivory among the plant diversity measures. The model with plant phylogenetic diversity as the predictor variable had the lowest AIC and BIC values as well as the highest loglikelihood (Table 1). In the full beta regression model, increasing LUI and proportion of grasses decreased herbivory while plant species richness had no significant effect and phylogenetic diversity had a weak but significant positive effect on herbivory (Table 2). The full linear model showed similar results, but proportion 
of grasses had only a marginal negative effect on invertebrate herbivory (see Appendix A: Table 1). After accounting for the effects of region, LUI, proportion of grasses and plant species richness in ANOVA, plant phylogenetic diversity still explained some variation in herbivory, albeit the effect was weak (Table 3). Performing model selection (linear and beta regressions) based on AIC scores lead to exclusion of plant species richness from the best fitting linear and beta regression models (see Appendix A: Table 2).

We then used SEMs to test for the importance of direct and indirect pathway between land-use intensity and herbivory. According to the goodness of fit measures the model for Schorfheide was saturated. The model for all three regions combined provided the least close fit, whereas the models for Alb and Hainich provided a similarly good fit (Table 4). No correlation between the variables in our models was significant in all four models, indicating that the strength of the relationships differed between regions (Fig. 2). Increasing land-use intensity affected plant species richness negatively in all models except the Schorfheide-model. Similarly, land-use intensity decreased phylogenetic diversity in all models except in the Alb. Proportion of grasses was not affected by LUI in Hainich, Schorfheide and in all three regions combined, whereas in the Alb, LUI had a negative effect on the proportion of grasses (Fig. 2). In all models except for Schorfheide (though there was a similar trend), proportion of grasses decreased phylogenetic diversity of plant communities. A direct negative effect of LUI on herbivory was found in Schorfheide and across the three regions combined. Indirect negative effects of LUI on herbivory were mediated by changes in the plant phylogenetic diversity mainly in Hainich, whereas plant phylogenetic diversity significantly increased herbivory in the model for all regions combined, but did not affect herbivory in any single region. In Alb and Schorfheide the direct negative effects of LUI were higher than the indirect, while in Hainich the opposite was the case (Table 5, Fig. 2).

The proportion of variance in herbivory explained by land-use intensification, proportion of grasses, plant species richness and plant phylogenetic diversity differed among regions. Land-use intensity had in general the strongest effect on herbivory than any of the plant diversity metrics, except in one region (see Appendix A: Fig. 1). Out of the plant diversity metrics, phylogenetic diversity explained most of the variance in herbivory in two of the three regions and when all regions were combined. In one region (Alb), plant species richness explained the highest proportion in herbivory (see Appendix A: Fig. 1). 
We showed that plant phylogenetic diversity is a stronger predictor of invertebrate herbivory than plant species richness and proportion of grasses. It explained a significant proportion of variance in herbivory even after accounting for the effects of region, land-use intensity and the other plant diversity measures. Higher phylogenetic diversity was associated with a moderate increase in invertebrate herbivory, a result pointing to associational susceptibility of plant communities in managed grasslands. Land-use intensity had an overall direct negative effect on herbivory. Indirect effects were mediated by changes in plant phylogenetic diversity and via land-use induced changes in plant species richness, which affected plant phylogenetic diversity. The variation in the strength of relationships among regions suggests additional, region-specific processes.

\section{Effects of plant diversity on invertebrate herbivory}

Obtaining a more general picture on the effects of plant diversity on varying levels of invertebrate herbivory is unfortunately hampered because there are two approaches to assess herbivory, i.e. plant-specific herbivory ("phytometers"; (Gibson 2002) and community-wide herbivory. Results between studies using different approaches are likely not comparable (Meyer et al. submitted). In our study the community-wide approach was used but without considering plant-species specific herbivory data.

Our results are in accordance with previous studies that showed poor predictive power of plant species richness on community-based invertebrate herbivory (Hanley 2004; Scherber et al. 2010). In contrast, phylogenetic diversity best explained variability in invertebrate herbivory, probably because it comprises more information on herbivory related traits than species richness or single measures of functional composition of plant communities (Srivastava et al. 2012). Our study indicates that the definition of the plant species pool might have an effect on the outcome of herbivory analyses. Dinnage (2013), for example, found a negative relationship between herbivory and phylogenetic diversity of plants. He analyzed herbivory on forbs only, excluding grasses from the analysis. Including grasses into his analysis might have led to an even stronger negative effect of phylogenetic diversity of plants on herbivory. In our study the proportion of grasses had a negative effect on plant phylogenetic diversity, and thus decreased the positive effect of plant phylogenetic diversity on herbivory (Fig. 2). Thus, to predict the strength of the effects of phylogenetic diversity on community herbivory all groups should be included into the analyses of herbivory. 
of plant species richness, indicating that specialization of herbivores on certain host plant species or clades

281 drives invertebrate herbivory in our study sites.

282 Contrary to most studies focusing on the effects of phylogenetic diversity of plants on invertebrate herbivory (e.g. Jactel \& Brockerhoff 2007; Yguel et al. 2011; Dinnage 2013; Castagneyrol et al. 2014) we found a positive effect, suggesting that in Central European managed grasslands, associational susceptibility would rather than associational resistance drive the herbivory pattern. In a meta-analysis Parker et al. (2012) also found an increase in herbivory with increasing phylogenetic distance on community level across a broad range of different biomes, including terrestrial (grasslands, forests, deserts) as well as aquatic (marshes and lake bottoms) systems. Thus, the results of increasing herbivory with increasing phylogenetic diversity might be a more general pattern. The authors explained the stronger impact of herbivores with increasing phylogenetic diversity of plant communities by a higher pressure from generalist herbivores. This might be caused by either generalists being able to feed on a wide range of distantly related plant clades or feeding on the most abundant plants, which were also distantly related in the analyzed studies (Parker et al. 2012). Whether a similar mechanism forms the basis of the patterns observed in our study remains unclear, since we did not separately assess the proportion of herbivory damage caused by specialist (e.g. most leaf miners) and generalist (many leaf chewers) herbivores. In real landscapes, with their naturally high variation in multiple factors (e.g. high number of herbivore species, differences in plant and herbivore composition, temporal variation in occurrence and abundance, etc.) and across a large geographic area such differentiations would have been only possible, if at all, on the costs of the lower number of plots studied. Here experimental approaches with simplified artificial plant and herbivore communities are more promising to test these ideas. However, it has been shown that increasing land-use intensity favors generalist herbivores (Börschig et al. 2013; Simons et al. 2015), decreases the phylogenetic diversity of plant communities (Fig. 2; Egorov et al. 2014) and decreases invertebrate herbivory (Gossner et al. 2014) in our study sites, which supports the interpretation of a specialistsdriven or "cladophage"-driven (Dinnage 2013) increase of herbivory. Increasing herbivory with increasing plant diversity (associational susceptibility) is often associated with generalist herbivores that particularly benefit from dietary mixing (Bernays et al. 1994; Miura \& Ohsaki 2004). There is, however, evidence that associational susceptibility could also result from specialists affected by the resource dilution effect (Otway et al. 2005; Plath et al. 2012). In general, our results are in line with a former study that found associational susceptibility to be more likely to appear in insect herbivore-plant interactions (Barbosa et al. 2009). 
We are aware that the rates of herbivory in our study appear to be low. This might be the result of (1) restricting measured herbivory to arthropod consumers, (2) conducting a single herbivory assessment in spring (Gossner et al. 2014) as it has been shown that herbivory rates are higher in summer than in spring (Meyer et al. submitted), and (3) performing a detailed and conservative measurement of herbivory that does not include leaves that are consumed as a whole (Loranger et al. 2014). However, invertebrate herbivory in meadows and grasslands in general does not exceed 10\% (Scherber et al. 2006; Unsicker et al. 2006), and the herbivory rates measured in our study are in the low range reported in earlier studies of European grasslands (Meyer et al. submitted; Scherber et al. 2006; Unsicker et al. 2006; Loranger et al. 2014). While the ecological consequences of such small herbivory rates should not be overestimated, multifold anti-herbivore mechanisms in plants indicate that invertebrate herbivory is of importance for plants causing plants to invest resources into herbivory defense at the cost of reduced fitness (Koricheva 2002). In addition, at the ecosystem level, processes like nitrogen cycling are affected even by low herbivory rates (Hunter 2001) which thus are potentially important.

\section{Direct vs. indirect effects of land-use intensity on herbivory}

Land use can affect invertebrate herbivory in grasslands either directly (e.g. mowing reduces abundance of herbivores by mechanically killing them; Humbert et al. 2009) or indirectly by affecting herbivore abundance and diversity via altering plant community composition (e.g. fertilization and mowing changing competition among plant species (Klaus et al. 2013; Simons et al. 2014) and/or plant nitrogen content (Tylianakis et al. 2008; Klaus et al. 2011)). Although there were differences between regions, we could reveal some general patterns. First, the direct effect of LUI on herbivory was generally larger than the indirect effects. This suggests that a high proportion of the land-use caused variation in herbivory is not mediated by our descriptors of plant community and we thus might have missed important variables. These might include important plant traits that are not captured by our plant phylogenetic diversity (i.e. have no phylogenetic signal). Another important point is that we are not testing changes in herbivory that are caused by land-use induced changes in the invertebrate communities. Invertebrate abundance and species richness increase herbivory (Ebeling et al. 2014), yet both are decreasing with increasing land-use intensity (Allan et al. 2014; Gossner et al. 2014; Simons et al. 2014). Incorporating this data would be a next step to complement our understanding of the land-use effects on the herbivory-biodiversity relationship. Second, land use decreased the positive effect of phylogenetic diversity on herbivory by reducing phylogenetic diversity directly (Egorov et al. 2014) and indirectly through changes 
in plant species richness (Socher et al. 2012). However, the structural equation model showed no significant indirect negative effect of land-use intensity on herbivory mediated by plant species richness or plant phylogenetic diversity when all three regions were analyzed together. This might be caused by different pathways being prevalent in the different regions. Separate models for each region showed that direct and indirect effects of land use vary between regions. Regional peculiarities (e.g. soil type and climate) can alter the effect of land use on plant diversity (Socher et al. 2012). In addition, the relative proportion of variance in herbivory explained by land-use intensity and plant diversity differed among our study regions (see Appendix A: Fig. 1). Possible explanations for this might be differences in the composition of plant communities or herbivore communities that respond to different aspects of plant diversity. This calls for caution when trying to apply general assumptions based on results from a single region.

\section{Conclusion}

348 We show that phylogenetic diversity of plants is a better predictor of invertebrate herbivory in managed grasslands than plant species richness, albeit not the strongest compared to land use. According to our results, herbivory related traits seem to be better represented by plant phylogenetic diversity than by species richness per se, which is in accordance with other studies dealing with the relations between traits and diversity measures (reviewed in Srivastava et al. 2012). Community phylogenetics provides a useful framework when analyzing herbivory and may improve our understanding about the mechanisms causing different levels of herbivory. However, additional information on specialization of involved herbivores and data on their diversity or abundance is necessary to conclusively resolve the underlying mechanisms. Therefore experiments are needed. Future studies of community-level herbivory should also try to quantify herbivory for each plant species separately or at least for each plant functional group (grasses, legumes, etc.). Such differentiations will allow much more detailed analyses on the causes of varying levels of herbivory among plant species and among communities. 
361 We thank the managers of the three Exploratories, Kirsten Reichel-Jung, Swen Renner, Katrin Hartwich,

362 Sonja Gockel, Kerstin Wiesner, and Martin Gorke for their work in maintaining the plot and project 363 infrastructure; Christiane Fischer and Simone Pfeiffer for giving support through the central office,

364 Michael Owonibi for managing the central data base, and Markus Fischer, Eduard Linsenmair, Dominik

365 Hessenmöller, Jens Nieschulze, Daniel Prati, Ingo Schöning, François Buscot, Ernst-Detlef Schulze,

366 and the late Elisabeth Kalko for their role in setting up the Biodiversity Exploratories project.

368 The work has been funded by the DFG Priority Program 1374 "Infrastructure-Biodiversity369 Exploratories" (BR 1967/9-1). Field work permits were issued by the responsible state environmental 370 offices of Baden-Württemberg, Thüringen, and Brandenburg (according to $§ 72 \mathrm{BbgNatSchG).}$ 
Supplementary data associated with this article can be found, in the online version, at XXXXX.

\section{References}

Allan E, Bossdorf O, Dormann CF, et al. (2014) Inter-annual variation in land-use intensity enhances grassland multidiversity. PNAS

Barbosa P, Hines J, Kaplan I, et al. (2009) Associational Resistance and Associational Susceptibility: Having Right or Wrong Neighbors. Annu Rev Ecol Evol Syst 40:1-20. doi: 10.1146/annurev.ecolsys.110308.120242

Bernays EA, Bright KL, Gonzalez N, Angel J (1994) Dietary Mixing in a Generalist Herbivore: Tests of Two Hypotheses. Ecology 75:1997-2006. doi: 10.2307/1941604

Blüthgen N, Dormann CF, Prati D, et al. (2012) A quantitative index of land-use intensity in grasslands: Integrating mowing, grazing and fertilization. Basic Appl Ecol 13:207-220. doi: 10.1016/j.baae.2012.04.001

Börschig C, Klein A-M, von Wehrden H, Krauss J (2013) Traits of butterfly communities change from specialist to generalist characteristics with increasing land-use intensity. Basic Appl Ecol 14:547-554. doi: 10.1016/j.baae.2013.09.002

Castagneyrol B, Jactel H, Vacher C, et al. (2014) Effects of plant phylogenetic diversity on herbivory depend on herbivore specialization. J Appl Ecol 51:134-141.

Cribari-Neto F, Zeileis A (2010) Beta Regression in R. J Stat Softw. doi: 10.18637/jss.v034.i02

Dinnage R (2013) Phylogenetic diversity of plants alters the effect of species richness on invertebrate herbivory. PeerJ 1:e93. doi: 10.7717/peerj.93

Dinnage R (2009) Disturbance Alters the Phylogenetic Composition and Structure of Plant Communities in an Old Field System. PLoS ONE 4:e7071. doi: 10.1371/journal.pone.0007071

Durka W, Michalski SG (2012) Daphne: a dated phylogeny of a large European flora for phylogenetically informed ecological analyses. Ecology 93:2297-2297. doi: 10.1890/12-0743.1

Ebeling A, Meyer ST, Abbas M, et al. (2014) Plant Diversity Impacts Decomposition and Herbivory via Changes in Aboveground Arthropods. PLoS ONE 9:e106529. doi: 10.1371/journal.pone.0106529

Egorov E, Prati D, Durka W, et al. (2014) Does Land-Use Intensification Decrease Plant Phylogenetic Diversity in Local Grasslands? PLoS ONE 9:e103252. doi: 10.1371/journal.pone.0103252

Fischer M, Bossdorf O, Gockel S, et al. (2010) Implementing large-scale and long-term functional biodiversity research: The Biodiversity Exploratories. Basic Appl Ecol 11:473-485. doi: 10.1016/j.baae.2010.07.009

Gibson DJ (2002) Methods in comparative plant population ecology. Oxford University Press ; Oxford University Press, Oxford: New York 
Gossner MM, Weisser WW, Meyer ST (2014) Invertebrate herbivory decreases along a gradient of increasing land-use intensity in German grasslands. Basic Appl Ecol 15:347-352. doi: 10.1016/j.baae.2014.03.003

Guyot V, Castagneyrol B, Vialatte A, et al. (2016) Tree diversity reduces pest damage in mature forests across Europe. Biol Lett 12:20151037. doi: 10.1098/rsbl.2015.1037

Hanley ME (2004) Seedling herbivory and the influence of plant species richness in seedling neighbourhoods. Plant Ecol 170:35-41.

Himanen SJ, Blande JD, Klemola T, et al. (2010) Birch (Betula spp.) leaves adsorb and re-release volatiles specific to neighbouring plants - a mechanism for associational herbivore resistance? New Phytol 186:722-732. doi: 10.1111/j.1469-8137.2010.03220.x

Humbert J-Y, Ghazoul J, Walter T (2009) Meadow harvesting techniques and their impacts on field fauna. Agric Ecosyst Environ 130:1-8. doi: 10.1016/j.agee.2008.11.014

Hunter MD (2001) Insect population dynamics meets ecosystem ecology: effects of herbivory on soil nutrient dynamics. Agric For Entomol 3:77-84. doi: 10.1046/j.1461-9563.2001.00100.x

Jactel H, Brockerhoff EG (2007) Tree diversity reduces herbivory by forest insects. Ecol Lett 10:835848. doi: $10.1111 / \mathrm{j} .1461-0248.2007 .01073 . x$

Kambach S, Kühn I, Castagneyrol B, Bruelheide H (2016) The Impact of Tree Diversity on Different Aspects of Insect Herbivory along a Global Temperature Gradient - A Meta-Analysis. PLOS ONE 11:e0165815. doi: 10.1371/journal.pone.0165815

Kembel SW, Cowan PD, Helmus MR, et al. (2010) Picante: R tools for integrating phylogenies and ecology. Bioinformatics 26:1463-1464. doi: 10.1093/bioinformatics/btq166

Klaus VH, Kleinebecker T, Hölzel N, et al. (2011) Nutrient concentrations and fibre contents of plant community biomass reflect species richness patterns along a broad range of land-use intensities among agricultural grasslands. Perspect Plant Ecol Evol Syst 13:287-295. doi: 10.1016/j.ppees.2011.07.001

Klaus VH, Kleinebecker T, Prati D, et al. (2013) Does organic grassland farming benefit plant and arthropod diversity at the expense of yield and soil fertility? Agric Ecosyst Environ 177:1-9. doi: 10.1016/j.agee.2013.05.019

Koricheva J (2002) META-ANALYSIS OF SOURCES OF VARIATION IN FITNESS COSTS OF PLANT ANTIHERBIVORE DEFENSES. Ecology 83:176-190. doi: 10.1890/00129658(2002)083[0176:MAOSOV]2.0.CO;2

Letourneau DK, Armbrecht I, Rivera BS, et al. (2011) Does plant diversity benefit agroecosystems? A synthetic review. Ecol Appl Publ Ecol Soc Am 21:9-21.

Loranger H, Weisser WW, Ebeling A, et al. (2014) Invertebrate herbivory increases along an experimental gradient of grassland plant diversity. Oecologia 174:183-193. doi: $10.1007 / \mathrm{s} 00442-013-2741-5$

Meyer ST, Scheithe L, Hertzog L, et al. (submitted) Consistent increase of herbivory along two experimental plant diversity gradients over multiple years. submitted

Miura K, Ohsaki N (2004) Diet mixing and its effect on polyphagous grasshopper nymphs. Ecol Res 19:269-274. doi: 10.1111/j.1440-1703.2004.00635.x

Otway SJ, Hector A, Lawton JH (2005) Resource dilution effects on specialist insect herbivores in a 
grassland biodiversity experiment. J Anim Ecol 74:234-240.

Parker JD, Burkepile DE, Lajeunesse MJ, Lind EM (2012) Phylogenetic isolation increases plant success despite increasing susceptibility to generalist herbivores: Phylogenetic relatedness and invasion success. Divers Distrib 18:1-9. doi: 10.1111/j.1472-4642.2011.00806.x

Plath M, Dorn S, Riedel J, et al. (2012) Associational resistance and associational susceptibility: specialist herbivores show contrasting responses to tree stand diversification. Oecologia 169:477-487. doi: 10.1007/s00442-011-2215-6

R Core Team (2014) R: A language and environment for statistical computing. R Foundation for Statistical Computing, Vienna, Austria

Root RB (1973) Organization of a Plant-Arthropod Association in Simple and Diverse Habitats: The Fauna of Collards (Brassica Oleracea). Ecol Monogr 43:95-124.

Rosseel Y (2012) lavaan: An R package for structural equation modeling. J Stat Softw 48:1-36.

Scherber C, Heimann J, Köhler G, et al. (2010) Functional identity versus species richness: herbivory resistance in plant communities. Oecologia 163:707-717. doi: 10.1007/s00442-010-1625-1

Scherber C, Mwangi PN, Temperton VM, et al. (2006) Effects of plant diversity on invertebrate herbivory in experimental grassland. Oecologia 147:489-500. doi: 10.1007/s00442-005-02813

Schuldt A, Assmann T, Bruelheide H, et al. (2014) Functional and phylogenetic diversity of woody plants drive herbivory in a highly diverse forest. New Phytol 202:864-873. doi: $10.1111 /$ nph.12695

Simons NK, Gossner MM, Lewinsohn TM, et al. (2014) Resource-Mediated Indirect Effects of Grassland Management on Arthropod Diversity. PLoS ONE 9:e107033. doi: 10.1371/journal.pone.0107033

Simons NK, Weisser WW, Gossner MM (2015) Multi-taxa approach shows consistent shifts in arthropod functional traits along grassland land-use intensity gradient. Ecology. doi: $10.1890 / 15-0616.1$

Socher SA, Prati D, Boch S, et al. (2012) Direct and productivity-mediated indirect effects of fertilization, mowing and grazing on grassland species richness. J Ecol 100:1391-1399. doi: 10.1111/j.1365-2745.2012.02020.x

Solomon BP (1981) Response of a Host-Specific Herbivore to Resource Density, Relative Abundance, and Phenology. Ecology 62:1205. doi: 10.2307/1937285

Srivastava DS, Cadotte MW, MacDonald AAM, et al. (2012) Phylogenetic diversity and the functioning of ecosystems. Ecol Lett n/a-n/a. doi: 10.1111/j.1461-0248.2012.01795.x

Stiling P, Rossi AM, Cattell MV (2003) Associational resistance mediated by natural enemies. Ecol Entomol 28:587-592. doi: 10.1046/j.1365-2311.2003.00546.x

Tahvanainen JO, Root RB (1972) The influence of vegetational diversity on the population ecology of a specialized herbivore, Phyllotreta cruciferae (Coleoptera: Chrysomelidae). Oecologia 10:321346. doi: 10.1007/BF00345736

Tylianakis JM, Didham RK, Bascompte J, Wardle DA (2008) Global change and species interactions in terrestrial ecosystems. Ecol Lett 11:1351-1363. doi: 10.1111/j.1461-0248.2008.01250.x 
Unsicker SB, Baer N, Kahmen A, et al. (2006) Invertebrate herbivory along a gradient of plant species diversity in extensively managed grasslands. Oecologia 150:233-246. doi: 10.1007/s00442006-0511-3

Unsicker SB, Oswald A, Köhler G, Weisser WW (2008) Complementarity effects through dietary mixing enhance the performance of a generalist insect herbivore. Oecologia 156:313-324. doi: 10.1007/s00442-008-0973-6

Webb CO, Ackerly DD, Kembel SW (2008) Phylocom: software for the analysis of phylogenetic community structure and trait evolution. Bioinformatics 24:2098-2100. doi: 10.1093/bioinformatics/btn358

Webb CO, Ackerly DD, McPeek MA, Donoghue MJ (2002) PHYLOGENIES AND COMMUNITY ECOLOGY. Annu Rev Ecol Syst 33:475-505. doi: 10.1146/annurev.ecolsys.33.010802.150448

Wink M (2003) Evolution of secondary metabolites from an ecological and molecular phylogenetic perspective. Phytochemistry 64:3-19. doi: 10.1016/S0031-9422(03)00300-5

Yguel B, Bailey R, Tosh ND, et al. (2011) Phytophagy on phylogenetically isolated trees: why hosts should escape their relatives: Phytophagy on phylogenetically isolated trees. Ecol Lett 14:11171124. doi: $10.1111 /$ j.1461-0248.2011.01680.x 
507 Fig. 1. Relationship between community-based herbivory (measured as percentage of leaf area 508 damaged) and phylogenetic diversity of plant communities (MPD in million years) in the three 509 regions in Germany $(n=145)$. Regression line is the prediction of the values for the beta 510 regression model (Proportion Herbivory $\sim$ MPD Plants) in the three regions combined $511 \quad\left(\mathrm{R}_{\text {pseudo }}{ }^{2}=0.16^{* * *}\right)$.

512 Fig. 2. Structural equation models of the relationships between land-use intensity (LUI), plant 513 diversity (proportion of grasses, plant species richness, plant phylogenetic diversity) and 514 herbivory in the three regions separately and combined. Path lines: dashed lines: negative path 515 coefficients, solid lines: positive path coefficients. Bold numbers indicate significant path 516 coefficients. 


\section{Tables}

518

Table 1. Summary of beta regressions. Effects of region and (a) proportion of grasses, (b) plant phylogenetic diversity and (c) plant species richness on invertebrate herbivory in 145 grassland plots in three regions in Germany. Goodness-of-fit measures and Pseudo $^{2}$ are given for each model. Bold and italic numbers indicate significant and marginally significant effects, respectively.

519

Estimate Std. Error $z$ value $p \quad$ AIC $\quad$ BIC $\quad$ R $_{\text {Pseudo }}{ }^{2}$ LogLik

\begin{tabular}{|c|c|c|c|c|c|c|c|c|c|}
\hline a & & & & & & -1096.1 & -1081.2 & 0.21 & 553.1 \\
\hline (Intercept) & -4.129 & 0.139 & -29.7 & $<0.001$ & $* * *$ & & & & \\
\hline Hainich & -0.518 & 0.117 & -4.4 & $<0.001$ & $* * *$ & & & & \\
\hline Schorfheide & -0.021 & 0.107 & -0.2 & 0.844 & & & & & \\
\hline Proportion Grasses & -0.412 & 0.206 & -2.0 & 0.046 & $*$ & & & & \\
\hline
\end{tabular}

\begin{tabular}{|c|c|c|c|c|c|c|c|c|c|}
\hline b & & & & & & -1105.5 & -1090.6 & 0.29 & 557.8 \\
\hline (Intercept) & -5.546 & 0.339 & -16.4 & $<0.001$ & $* * *$ & & & & \\
\hline Hainich & -0.390 & 0.118 & -3.3 & $<0.001$ & $* * *$ & & & & \\
\hline Schorfheide & 0.069 & 0.108 & 0.6 & 0.524 & & & & & \\
\hline Plant phylogenetic diversity & 0.006 & 0.002 & 3.6 & $<0.001$ & $* * *$ & & & & \\
\hline
\end{tabular}

\begin{tabular}{|c|c|c|c|c|c|c|c|c|c|}
\hline C & & & & & & -1103.4 & -1088.5 & 0.26 & 556.7 \\
\hline (Intercept) & -4.942 & 0.189 & -26.1 & $<0.001$ & $* * *$ & & & & \\
\hline Hainich & -0.531 & 0.114 & -4.7 & $<0.001$ & $* * *$ & & & & \\
\hline Schorfheide & 0.113 & 0.120 & 0.9 & 0.344 & & & & & \\
\hline Plant species richness & 0.019 & 0.005 & 3.4 & $<0.001$ & $* * *$ & & & & \\
\hline
\end{tabular}


Table 2. Beta regression summary. Effects of region, LUI, proportion of grasses, plant species richness and plant phylogenetic diversity on herbivory in the three regions $\left(\mathrm{R}_{\mathrm{pseudo}}{ }^{2}=0.38\right)$. Bold numbers indicate significant $p$-values.

\begin{tabular}{lccccll} 
& Estimate & Std. Error & $\boldsymbol{z}$ value & $\boldsymbol{p}$ & \\
(Intercept) & -4.389 & 0.492 & -8.92 & $<\mathbf{0 . 0 0 1}$ & $* * *$ \\
Hainich & -0.429 & 0.112 & -3.84 & $<\mathbf{0 . 0 0 1}$ & $* * *$ \\
Schorfheide & 0.129 & 0.122 & 1.06 & 0.288 & \\
Land-use intensity & -0.328 & 0.100 & -3.28 & $\mathbf{0 . 0 0 1}$ & $* *$ \\
Proportion grasses & -0.472 & 0.203 & -2.32 & $\mathbf{0 . 0 2 0}$ & $*$ \\
\hline Plant species richness & 0.004 & 0.007 & 0.61 & 0.544 & \\
Plant phylogenetic diversity & 0.003 & 0.002 & 1.99 & $\mathbf{0 . 0 4 7}$ & $*$
\end{tabular}

Table 3. Linear model summary. Effects of region, LUI, proportion of grasses, plant species richness and plant phylogenetic diversity on herbivory in the three regions. ANOVA table of the full model $\left(\mathrm{R}^{2}=0.32\right)$. Bold numbers indicate significant effects.

$\begin{array}{lcccc} & \text { Df } & \text { F } & \text { p } & \\ \text { Region } & 2 & 16.09 & <0.001 & * * * \\ \text { Land-use intensity } & 1 & 21.33 & <0.001 & * * * \\ \text { Proportion grasses } & 1 & 7.98 & \mathbf{0 . 0 0 5} & * * \\ \text { Plant species richness } & 1 & 0.82 & 0.365 & \\ \text { Plant phylogenetic diversity } & 1 & 4.28 & \mathbf{0 . 0 4 0} & * \\ \text { Residuals } & 138 & & & \end{array}$

Table 4. Goodness-of-fit measures from the output of the four structural equation models testing for correlations between land-use intensity, plant diversity and herbivory in the 145 grassland plots in three regions in Germany. GFI: Goodness-offit; RMSEA: root mean square error of approximation.

$\begin{array}{lcccccc}\text { ALB } & 0.41 & 1 & 0.51 & 0.996 & 0 & 642.2 \\ \text { HAINICH } & 0.18 & 1 & 0.67 & 0.998 & 0 & 684.5 \\ \text { SCHORFHEIDE } & 0 & 0 & \text { NA } & 1 & 0 & 360.5 \\ \text { ALL REGIONS } & 2.14 & 1 & 0.14 & 0.994 & 0.089 & 2081.4\end{array}$


Table 5. Direct, indirect and total effects of LUI on invertebrate herbivory in 145 grassland plots in three regions in Germany.

\begin{tabular}{l|c|c|c|c} 
& ALL & ALB & HAINICH & SCHORFHEIDE \\
\hline Direct & -0.37 & -0.26 & -0.19 & -0.31 \\
Indirect & 0.02 & -0.09 & -0.35 & -0.02 \\
Total & -0.35 & -0.35 & -0.54 & -0.33
\end{tabular}

